\title{
Gender Bias in High School Congressional Debate Scores
}

\author{
Amanda Myles ${ }^{1}$ \\ ${ }^{1}$ Mentor High School, Mentor, OH, USA
}

\section{$\underline{\text { ABSTRACT }}$}

Throughout history, stereotypes and negative ideology have led to gender inequality. This paper explores the presence of gender inequality in the scoring of high school congressional debate. The study conducted was a quantitative analysis of Ohio Speech and Debate Association tournament score sheets from 2013-2020. The rank total, preliminary result, and average preliminary result of each competitor of three tournaments per season were recorded to discover if one gender tends to score better than the other. The results showed that both genders have about equal percentages of participants who receive high scores (31.28\% of females and $32.64 \%$ of males), medium range scores (34.60\% of females and $32.32 \%$ of males), and low scores (34.12\% of females and $34.76 \%$ of males). Chi-square tests completed on the data showed no statistical significance in the difference between the scores of female and male participants ( $\mathrm{p}=.89481$ ). According to the data collected, there is no significant evidence of a gender bias present in the scoring of high school congressional debate.

\section{Introduction}

Women are often less inclined to participate in speech and debate due to the fact that their chances of success are reduced in comparison to their male counterparts (Tarakovsky, 2016). Founded in 1925, the National Forensics League, which is now commonly referred to as the National Speech and Debate Association, was created to augment the participation of high school students in speech and debate activities. The National Speech and Debate Association has a mission statement that emphasizes the importance of a "diverse community committed to empowering students" (National Speech and Debate Association, 2018). However, for many years, women have found it more arduous to score higher than their male counterparts. Although barriers to female involvement within the National Speech and Debate Association have been removed, data displays that there is a lack of female representation in debate competitions and awards. In 2018, only twenty-four percent of the quarter finalists were female, and six percent of finalists were females; the median number of females in final rounds was zero (Lynn \& Kawolics, 2018). Despite the efforts of the National Speech and Debate Association to create and foster an inclusive environment, female participants appear to still find securing a spot in the final rounds of debate tournaments an onerous endeavour. Women participants will lose a round for being "too aggressive," while men will be praised for their assertiveness (Kilpatrick, 2019). The discrepancy in the way female participants are judged in comparison with male participants on factors both genders display in debate rounds, such as passion or assertiveness, can be attributed to stereotypes of the female gender.

Girls are often viewed as "too emotional" in debates, which is a gender stereotype that has formed based on the ideas and perceptions of how females should behave compared to how men should act. Gender inequality has existed in our society throughout history, and women still frequently face this issue today in their daily lives. Unfair treatment towards women is often rooted in ideology; individuals have certain internalized conceptions of femininity and masculinity that influence their expectations for how each gender should act and how they should be treated by others (Jackson, 2018). An individual's ideology of a group of people, such as women, impacts the way they treat all people of that group. In fact, studies have shown that although decisions made by judges can be influenced by factors 
such as race, gender, and ethnicity, their decisions are most heavily influenced by their ideology (Harris \& Sen, 2018). An additional factor that largely contributes to the unequal treatment of the genders is the idea of stereotypes. Stereotypes are oversimplified and overgeneralized conceptions of a group, and they allow people to implicitly associate a gender with certain traits or attitudes. For example, women are often viewed as the more emotional gender as compared to men (Kilpatrick, 2019). This stereotype is very present in the lives of women, and this typecast can hinder their chances of success in many school activities, including debate.

There has been a wide variety of studies done on the presence of gender biases in the lives of high schoolers. According to "Gender Disparity in Education: A Challenge for Development," data presents that there are gender disparities present in education that lead to girls receiving a less desirable education in comparison to male students (Ghorayshi, 1993). There have even been studies conducted on the presence of gender disparities in specific areas of education, such as Reed's study of gender bias in music education in the peer-reviewed paper "Gender Bias in Music Education: Think Back and Look Forward." Evidence shows that thought processes on the roles of females and males in society lead to gender biases in music education that impacts the students' performance as well their passion for learning about music (Reed). The issue of gender biases is an important issue due to the fact that proclivities for one gender over the other have been studied in various disciplines. Additionally, recent research has shown that there is a bias present in the scoring of other areas of speech and debate, such as policy debate. An examination of policy debaters attending the National Debate Tournament found that only eight women were included in the final round of the annual tournament from its establishment in 1947 to the year 1985 (Logue, 1986). In addition to the evidence that there is a disparity in the scoring of the genders in policy debate, there is also research showing that Lincoln-Douglas debate includes a level of bias in its scores as well. In high school Lincoln-Douglas debate, scores tend to favor male participants over female participants, which leads to young women being discouraged to participate (Tartakovsky, 2016).

Although Lincoln Douglas debate, policy debate, and congressional debate are all activities that fit under the same general category of debate, there are significant differences in the way that each area of debate is conducted and scored. The National Speech and Debate Association includes a comprehensive variety of areas of debate to participate in, including Lincoln-Douglas, public forum, policy, and congressional debate. The area of debate which the new research will cover is congressional debate. Congressional debate is defined by the National Speech and Debate Association as "a mock legislative assembly competition where students draft proposed laws and resolutions, which their chambers later debate and vote for or against the legislation" (National Speech and Debate Association, 2017). In each congressional debate chamber, which usually includes from ten to thirty debaters, the individual participants each receive scores on their speeches and an overall rank against their multiple peers. In contrast, Lincoln-Douglas debate is formatted as a one-on-one debate, and policy debate and public forum debate include pairs of participants debating against another pair of students. The scoring of a round of Lincoln-Douglas debate, policy debate, and public forum debate is conducted by a single judge; whereas, congressional debate is scored by multiple judges. Previous research has studied gender biases in different areas of debate; however, the specific area of debate, congressional debate, has not been studied yet to determine if the scoring shows gender bias. This raises the question: Is there a gender bias evident in the scoring of high school congressional debate?

Due to the results of previous research conducted on gender disparities in Lincoln-Douglas debate, the findings of the new study are hypothesized to show that there is a tendency for women to receive lower scores than men. The purpose of this study is to determine if scoring in high school congressional debate is biased against one gender.

Participation in speech and debate allocates students with a plethora of benefits. As this is an activity that involves obtaining knowledge about numerous topics and learning skills to be able to defend a predetermined stance on the issues, this activity helps students to ameliorate their critical thinking skills, including analyzing, synthesizing, and critiquing content (Fisher, 2013). Students also become well versed in current real-world issues as they have to research information about their topics to prepare for debate competitions. A female student who anticipates that they will be judged based on a negative stereotype of their gender will miss the opportunity to improve their skills in researching and thinking critically through participation in debate. In addition, this activity helps students refine their 
writing and communication adroitness as they have to create convincing speeches and verbally defend their arguments against their opponents. Research has exhibited that participation in speech and debate activities leads to a positive impact on school measures such as school GPA and study retention (Minch, 2006). In the same vein, a study conducted by Peters in the document "An Investigation into the Relationship Between Participation in Competitive Forensics and Standardized Test Scores" displayed that students with experience in competitive debate score significantly higher in state administered reading and writing tests than students who do not participate in debate. Female participants who are less likely to participate in debate as a result of a fear of unequal chance to succeed against their male peers miss the opportunity to obtain the abundant amount of scholarly advantages connected with debate participation. Moreover, in addition to the scholarly benefits of debate, students obtain an extensive level of preparedness for the workforce and occupational success due to the fact that the skills that participation in debate fosters are highly valued in the business world (Minch, 2006). Speech and debate activities create an environment that nurtures a student's intellect and has many long-term benefits. The value of the new research is to help spread awareness about the issue in order to make the scoring of high school congressional debate fairer for both females and males. If both genders are assured that they will have an equal chance of success and will not be judged based on stereotypes, then more students will be inclined to participate and receive the intellectual benefits of congressional debate.

\section{Method}

The method design that was most reliable and beneficial for discovering if there is a gender bias in the scoring of congressional debate was the approach of a quantitative analysis of past scores. This method relied on real debate scores to find discrepancies in the level of equality of both genders' scores, rather than relying on information that may have included opinions, such as a survey of debate students or debate judges. Additionally, this design has been effective in peer-reviewed research that has studied other areas of debate, such as Tartakovsky's study on LincolnDouglas debate in the paper "Gender Disparities in Competitive High School Debate New Evidence from Comprehensive Tournament Results Data" and Kawolics' study on public forum debate in the paper "Public Forum Does Need to Change: A Research-Based Evaluation." Both papers have used the approach of a quantitative analysis of past tournament scores, and their results have shown the method to be effective and successful in discovering if there is a gender bias in the scores of Lincoln-Douglas and public forum debate.

Similarly, the method in this study analyzed the scores of high school congressional debate competitors from multiple Ohio Speech and Debate Association (OSDA) tournaments, spanning from 2013 to 2020. The OSDA website releases score sheets of tournaments from 2013 to present day for the public to view. These score sheets include the scores of all events in the tournament for high school students in Ohio. Therefore, this study did not require human participant recruitment. An example of the OSDA tournament score sheets that were analyzed can be viewed in the appendix.

In order to ensure that the data is extensive and can be representative of high school congressional debate, data from multiple tournaments over each debate season available to the public were analyzed. As debate participants and judges can vary from season to season, the method used data from the first tournament of each debate season, the median tournament from each season, and the final available tournament from each season from 2013-2020. This ensured that the data collected included a variety of judges and congressional debate participants. The data points that were collected in this quantitative analysis are from high school students in Ohio congressional debate from grade nine to grade twelve; therefore, the students have a range of experience and practice with congressional debate.

This quantitative analysis collected primarily quantitative information, along with the qualitative data of the gender of each participant. The OSDA tournament score sheets include the names of each participant along with their scores; therefore, this analysis used the names of each participant to determine their gender. Due to the fact that there are gender neutral names included on the tournament sheets, additional information was required. In order to obtain clarification of the gender of the parties in question, debate coaches of each team were contacted. If the gender of participants was undetermined, their information was not included in this data. 
Along with the qualitative data of each participant's gender, the quantitative data that must be collected include the debater's rank total, preliminary result, and their average preliminary result. In each session of student congress, participants are scored based on their given speeches and their ability to defend their argument against opposing debaters in their session; among the scores they receive are rank totals and preliminary results. Students are given a rank from each judge in their chamber in the preliminary session; this gives each student multiple preliminary scores. The sum of all of the preliminary scores from each judge is the debater's rank total. The preliminary result of each debater is their overall rank against their peers based on their preliminary scores. In order to determine the average preliminary result of each student, the rank total, which is the sum of the judge's preliminary scores, was divided by the number of preliminary scores that each participant receives. The tournament sheets detail the exact preliminary scores obtained for every debater; therefore, the number of preliminary scores per student was able to be obtained to find the average preliminary results.

To analyze the content of the OSDA tournament sheets and determine if the data shows a gender bias in congressional debate scoring, the data from each tournament was transferred from the tournament sheet to a spreadsheet on Google Sheets, as shown in Table 1. Considering that this study collected data from three tournaments per season from 2013 to 2020, the data includes twenty-one tournaments. The three tournaments for each season were organized into a tab for each season. This allowed the study to analyze trends in each season to determine if the new data can display significant findings about the scoring of congressional debate throughout the seasons. With completed collection of the rank total, preliminary result, and average preliminary result of each participant collected, each specific tournament of the twenty-one total tournaments was analyzed to determine and record the participants who scored in the highest third of the tournament, the participants who scored in the middle range of the tournament, and the participants who received the lowest third of the total scores of the tournament. With this data, the scores that female debaters received were measured and compared to the scores that male debaters received in high school congressional debate in order to determine if scoring in congressional debate activities is biased to favor one gender over the other.

Table 1. Data Collection Tool: This table shows only one of the twenty-one tournaments collected in Google Sheets. The same setup was used for the collection of all tournaments.

\begin{tabular}{|c|c|c|c|c|c|}
\hline $\begin{array}{c}\text { Date of } \\
\text { Tournament }\end{array}$ & Gender of Competitor & Rank Total & Prelim Results & $\begin{array}{c}\text { Average Prelim } \\
\text { Result }\end{array}$ & $\begin{array}{c}\text { High, Medium, } \\
\text { or Low Score** }\end{array}$ \\
\hline $10 / 20 / 2018$ & Male & 31 & 1 & 2.58 & High \\
\hline $10 / 20 / 2018$ & Male & 39 & 2 & 3.25 & High \\
\hline $10 / 20 / 2018$ & Male & 75 & 6 & 6.25 & High \\
\hline $10 / 20 / 2018$ & Male & 81 & 7 & 6.75 & High \\
\hline $10 / 20 / 2018$ & Female & 90 & 8 & 7.50 & Medium \\
\hline $10 / 20 / 2018$ & Male & 98 & 8 & 8.17 & Medium \\
\hline $10 / 20 / 2018$ & Female & 102 & 10 & 8.50 & Medium \\
\hline $10 / 20 / 2018$ & Male & 119 & 11 & 9.92 & Medium \\
\hline $10 / 20 / 2018$ & Male & 120 & 12 & 10.00 & Low \\
\hline $10 / 20 / 2018$ & Male & 120 & 13 & 10.00 & Low \\
\hline $10 / 20 / 2018$ & Female & 124 & 14 & 10.33 & Low \\
\hline $10 / 20 / 2018$ & Female & 130 & 15 & 10.83 & Low \\
\hline
\end{tabular}

**High scores include the top third of scores in each tournament, medium scores are the middle third of scores, and low scores are the lowest third of scores in each tournament. 


\section{Results}

The final data consists of twenty-one total tournaments, including three tournaments per season from the 2013-2014 season to the most recent 2019-2020 season. Out of the total twenty-one tournaments, there were 493 participants that comprised the data in this quantitative analysis of high school congressional debate scores. The final data collected in this study consists of 211 female participants and 282 male participants. The participants included students in all of the high school grade levels, grade nine through grade twelve. The tournaments analyzed included multiple debate judges from the several areas of Ohio that hold and attend speech and debate competitions. Upon collecting and viewing each participant's rank total, preliminary results, and average preliminary results, scores of each congressional debate tournament were divided into three categories: high scores, medium scores, and low scores. As shown in Table 2 below, the data displayed that 66 (31.28\%) of the 211 female participants received a high score, 73 (34.60\%) female participants scored in the middle range, and $72(34.12 \%)$ female participants scored in the lowest third of their tournament. In comparison, 92 (32.64\%) of the 282 male participants received a high score, 92 (32.62\%) male participants scored in the middle, and $98(34.76 \%)$ male participants scored low.

Table 2. Gender of Participants vs Number of High, Medium, and Low Scores

\begin{tabular}{|l|c|l|c|}
\hline \multicolumn{2}{|c|}{ Female Participants } & \multicolumn{2}{c|}{ Male Participants } \\
\hline Number of High Scores & $66(31.28 \%)$ & Number of High Scores & $92(32.64 \%)$ \\
Number of Medium Scores & $73(34.60 \%)$ & Number of Medium Scores & $92(32.62 \%)$ \\
Number of Low Scores & $72(34.12 \%)$ & Number of Low Scores & $98(34.76 \%)$ \\
\hline $\begin{array}{l}\text { Total Number of Female Par- } \\
\text { ticipant Scores }\end{array}$ & $211(100 \%)$ & $\begin{array}{l}\text { Total Number of Male Participant } \\
\text { Scores }\end{array}$ & $282(100 \%)$ \\
\hline
\end{tabular}

Additionally, the gender of each participant that earned the highest score of their tournament, the first-place rank, was collected for all twenty-one tournaments. Out of the first-place winners of each of the twenty-one OSDA congressional debate tournaments collected and analyzed in this study, twelve winners were female, and nine were male participants.

\section{Analysis}

In order to analyze the new data and determine if a gender bias is present in high school congressional debate scoring, multiple tests had to be done on the data collected. A chi-square test of contingency was completed to compare the male participants to the female participants on the amount of high, medium, and low scores they received total. This test is done to determine if the differences in the results of the categories being tested can be explained by chance or if they are statistically significant. After completing this test, it was determined that the p-value, which is the probability value, was .89481 . The results of this chi-square test of contingency show that the discrepancies in the number of high scores, medium scores, and low scores for different genders is not statistically significant at a confidence level 
of $80 \%$ or higher. Therefore, there is no significant evidence that gender differences impact a debater's ability to score well against their peers in congressional debate tournaments.

To further analyze the data collected in this quantitative analysis of congressional debate scores, an additional chi-square test for goodness of fit was completed to compare the expected number of first place wins for each gender to the observed number of first place wins for each gender. A chi-square test for goodness of fit is done to determine if the observed values of a study significantly differ from the values that are expected to be collected. Due to the fact that $53.7 \%$ of the total 493 participants were male and $42.7 \%$ were female, the expected amount of first place wins for males was twelve of the twenty-one tournaments, and females were expected to have nine first place wins of the total twenty-one tournaments. However, the observed data displayed males won the first-place rank in nine tournaments, and females won first place in twelve tournaments. After the data was tested for goodness of fit, the p-value was .18088. The result of this chi-square test for goodness of fit was not statistically significant at a confidence level of $80 \%$ or higher; therefore, there was no significant difference in the expected number of first place wins per gender and the observed number of first place wins per gender from the data collected in this study.

Since neither chi-square test resulted in a statistically significant p-value, the new study shows that there is no significant evidence of a gender bias present in the scoring of high school congressional debate. The results of both the chi-square test of contingency and the chi-square test for goodness of fit display that the scores collected from the OSDA tournaments analyzed in this study are fair and equitable for both genders.

\section{Conclusion}

Based on the results of this study, the conclusion can be made that there is no significant gender disparity in the scoring of high school congressional debate. The chi-square tests, including the chi-square test of contingency and the chisquare test for goodness of fit, that were done on data from the twenty-one tournament score sheets used in this study displayed no statistical significance.

The findings of this study are beneficial to the population of female high school students. The result that a participant's gender does not impact their ability to strive in congressional debate should allow female congressional debate participants to feel progressively more confident in the fact that they will have an equal chance of success in debate as male participants do. Female participants should be less likely to succumb to the stereotype threat, which is defined by the National Institute of Health as a psychological threat that one will be assessed based on a negative stereotype for a group. In the same vein, the findings of this research should promote an increase in female participation in debate. For many years, women have been less encouraged to participate in any type of debate due to a fear that they will be judged based on the stereotype that women are too emotional to successfully compete in debate. In fact, of the total 124 participants in the National Debate Tournament in 1984, only $15 \%$ of the participants were female while $85 \%$ were male (Friedley \& Manchester, 1985). The stereotype threat that discourages women to participate in debate still exists today as the data collected in this quantitative analysis displayed that there are more male participants in congressional debate than there were female participants, with the data including 282 male participants and only 211 female participants. The stereotype threat that exists for women in debate may be the reason female participation numbers are lower than male participation numbers, despite the statistically equivalent scores collected in this study.

As female students become assured that they can do well in congressional debate, more female high school students should be inclined to participate in speech and debate activities, and, consequently, receive a plethora of the many intellectual benefits associated with speech and debate participation. Because the findings of this study show that there is no significant evidence of a gender bias in congressional debate scoring, an increasing number of female participants will be able to improve their skills in critical thinking, writing, communication, and critiquing content, which are crucial in school and a multitude of future occupations.

In the future, additional research could be done on the topic of gender disparities in congressional debate scoring by broadening the reach of the data collection. One limitation of the quantitative analysis of debate scores completed in this study is the fact that the scores that were analyzed only included results from Ohio speech and debate 
tournaments. This could impact the ability for this research to be generalized for all high school congressional debaters due to the fact that training for judges and students is not identical in all states. If future researchers obtain access to a greater number of tournaments from all over the nation, the results may differ as there would be a greater population of debate students studied. With data from across the nation collected, researchers could also compare if trends in congressional debate scores correspond in all states or find if different states show more of a gender bias in scoring than others.

There are more limitations from this study that could be overcome in future research. This study compared students from grade nine through grade twelve, so there are students with different levels of experience and training. Congressional debate rounds include students of varying experience levels and grade levels. Freshman year is full of academic firsts, whereas a student in their senior year is well adjusted to their scholarly activities (Hodon, 2020). New freshman students are still learning about how to successfully compete in debate, while experienced upperclassmen are adjusted well to debate. A student in their senior year with four years of experience in congressional debate tournaments would be more likely to score higher than a freshman student with less than a year of experience, regardless of their gender. Additional analyses could be done to focus on one specific grade or experience level, like high school seniors with four years of experience, to see if one gender scores better than the other. A study that analyzes the difference in scores of female and male participants with a constant level of experience in all participants may yield different results than the results of this research. Further studies with a focus on one level of experience would eliminate extraneous variables of varying experience level in this study that may have had an impact on the findings that resulted from this study.

Additionally, future research could be consummated to analyze if the scoring of each gender depends on the gender of the tournaments' judges. This quantitative analysis found that there is generally no gender bias in congressional debate scoring; however, this research focused on the genders of the debaters rather than focusing on the genders of the tournaments' judges. A future quantitative analysis could collect the gender of each tournament's judges and collect the scores they gave to female debate students and male debate students. Studies have shown that children report feeling more positively toward others of their own sex, and this feeling tended to increase with age (Yee \& Brown, 1994). Further studies could determine if this feeling of increased positivity towards members of a person's own gender that were shown to be present in children are also present in high school debate judges. If the gender of the judges of each tournament were collected, the researcher would be able to determine if either gender tends to give more favorable scores to students of their own gender in debates. This idea for further research would be able to broaden the knowledge of the public on gender biases in high school speech and debate scoring. Additionally, this data could be used to evaluate if the factor of the judges' genders impacts the scores of debates and drives the stereotype that women perform worse in debate activities.

\section{References}

Fisher, D. (2013, April). Speaking and Debating Open doors for new standards. Retrieved from https://www.questia.com/magazine/1G1-326981232/speaking-and-debating-open-doors-for-new-standards

Friedley, S. A., \& Manchester, B. B. (1985). An Analysis of Male/Female Participation at Select National Championships. Retrieved from http://www.nationalforensicjournal.org/uploads/9/1/9/3/91938460/vol3nol.pdf

Ghorayshi, P. (1993). Gender Disparity in Education: A Challenge for Development. International Journal of Contemporary Sociology, 30(2), 199-215. Retrieved from http://search.ebscohost.com/login.aspx?direct $=$ true $\& \mathrm{db}=$ sih $\& A N=23113466 \&$ site $=$ ehost-live 
Hodon, S. (2020). Freshman vs. Senior Year of High School: The Biggest Differences. Retrieved from https://www.collegexpress.com/articles-and-advice/student-life/articles/living-campus/freshman-vs-senior-yearhigh-school-biggest-differences/

Jackson, R. M. (2018). Seminar: What Causes Gender Inequality? Retrieved from https://www.nyu.edu/classes/jackson/causes.of.gender.inequality/.

Kawolics, R. (2019, June 20). Public Forum Does Need to Change: A Research-Based Evaluation. Retrieved from https://beyondresolved.org/2019/06/20/pfchange/

Kilpatrick, M. (2019, November 14). High schooler works to address implicit bias in debate judging. Retrieved from https://www.cleveland.com/metro/2019/11/high-schooler-works-to-address-implicit-bias-in-debate-judging.html.

Logue, B. (1986). CEDA: male/female participation levels-a research report, Contemporary Argumentation and Debate 7, 64-75.

Lynn, J., \& Kawolics, R. (2018, April 14). 2018 April/May Rostrum. Retrieved from https://issuu.com/speechanddebate/docs/2018 april may rostrum web/32.

Minch, K. (2006). The Value of Speech, Debate and Theater Activities: Making the Case for Forensics. Retrieved from https://www.speechanddebate.org/wp-content/uploads/Making-The-Case-NFHS.pdf.

National Institutes of Health. (2017). Stereotype Threat. Retrieved from https://diversity.nih.gov/sociocultural-factors/stereotype-threat

National Speech and Debate Association. (2017). Congressional Debate: Guide. Retrieved from https://www.speechanddebate.org/wp-content/uploads/2017-Congressional-Debate-Guide.pdf. National Speech and Debate Association. (2018). High School Unified Manual. Retrieved from https://www.speechanddebate.org/wp-content/uploads/High-School-Unified-Manual-2017-2018.pdf.

Ohio Speech and Debate Association. (n.d.). The OSDA Results. Retrieved April 19, 2020, from https://sites.google.com/view/theosda/results?authuser $=0$

Peters, T. L. (n.d.). An Investigation into the Relationship Between Participation in Competitive Forensics and Standardized Test Scores. Retrieved from https://www.bluevalleyk12.org/cms/lib/ks02212623/Centricity/Domain/2061/ userdocs publicDocs PetersResearch.pdf

Reed, M. T. (n.d.). Gender Bias in Music Education: Think Back and Look Forward. Retrieved from http://web.a.ebscohost.com/ehost/pdfviewer/pdfviewer?vid=9\&sid=1ef23133-4ee1-451b-8922-137a253f8052@sessionmgr4007

Tartakovsky, D. (2016, August 9). New Evidence on Gender Disparities in Competitive High School Lincoln-Douglas Debate. Retrieved from https://www.vbriefly.com/2016/05/15/new-evidence-on-gender-disparities-in-competitive-high-school-lincoln-douglas-debate/.

Yee, M., \& Brown, R. (1994, June). The Development of Gender Differentiation in Young Children. Retrieved from https://www.ncbi.nlm.nih.gov/pubmed/8044502/ 